\title{
IMPLEMENTASI JARINGAN FIBER TO THE HOME (FTTH) DENGAN TEKNOLOGI GIGABIT PASSIVE OPTICAL NETWORK (GPON)
}

\author{
Sunarsan Sitohang \\ Fakultas Teknik dan Komputer, Program Studi Teknik Informatika \\ Universitas Putera Batam \\ Email: ssunarsan@gmail.com \\ Sabbram Agus Setiawan \\ Fakultas Teknik dan Komputer, Program Studi Teknik Informatika \\ Universitas Putera Batam \\ Email: bray.coolmen@gmail.com
}

\begin{abstract}
ABSTRAK
Penelitian ini dilakukan dengan perancangan jaringan Fiber to the home (FTTH) menggunakan teknologi gigabit passive optical network (GPON) dengan melihat parameter power link budget dan redaman yang dihasilkan. Nilai dari parameter tersebut kemudian dibandingkan dengan standar dari peusahaan Telkom sebagai perusahaan yang akan membangun jaringan FTTH pada lokasi penelitian. Link power budget digunakan untuk memperoleh besaran dari redaman. Standar besaran redaman Telkom adalah - $28 \mathrm{dBm}$. Berdasarkan hasil pengujian jaringan FTTH diperoleh redaman downlink sebesar -25.09897 dBm dan redaman uplink sebesar -25.74997 dBm. Selanjutnya kinerja jaringan diukur dengan parameter quality of service (QoS) dengan tujuan untuk mengetahui kualitas layanan data. Parameter QoS yang digunakan adalah bandwidth, packet loss, delay, jitter, dan throughput. Selanjutnya website yang diakses sebagai bahan proses analisis untuk mendapatkan besaran parameter QoS adalah yahoo.com, facebook, dan kompasiana.com. hasil analisis data menunjukkan bahwa rata-rata QoS untuk ketiga website diatas secara berurutan adalah bandwith sebesar $1828.6 \mathrm{kbps}$, packet loss sebesar $0.9 \mathrm{kbps}$, delay sebesar $37.89 \mathrm{~ms}$, jitter sebesar $2.81 \mathrm{~ms}$ dan troughtput sebesar 0.93 .
\end{abstract}

Kata kunci: FTTH; GPON; QoS; jaringan.

\begin{abstract}
This research is done by designing Fiber to the home network (FTTH) using gigabit passive optical network (GPON) technology by looking at power link budget and attenuation parameters. The value of these parameters is then compared with the standard of Telkom's company as the company that will build FTTH network in the research location. Power budget link is used to obtain the quantity of attenuation. Standard dimension of Telkom attenuation is $-28 \mathrm{dBm}$. Based on FTTH network test results obtained attenuation downlink equal to $-25.09897 \mathrm{dBm}$ and attenuation of uplink equal to $-25.74997 \mathrm{dBm}$. Furthermore, network performance is measured with quality of service parameters (QoS) in order to know the quality of data services. QoS parameters used are bandwidth, packet loss, delay, jitter, and throughput. Furthermore, the website accessed as a process of analysis materials to obtain the quantity of QoS parameters is yahoo.com, facebook, and kompasiana.com. the result of data analysis shows that the average QoS for the three websites above are sequentially $1828.6 \mathrm{kbps}$ bandwidth, packet loss of 0.9 kbps, delay of $37.89 \mathrm{~ms}$, jitter of $2.81 \mathrm{~ms}$ and troughtput of 0.93.
\end{abstract}

Keywords: FTTH; GPON; QoS; network.

\section{PENDAHULUAN}

Perkembangan teknologi telekomunikasi didunia ini mengalami perubahan dengan sangat cepat. Sebagian besar perubahan dilakukan pada teknologi akses, khususnya dijalur data berkecepatan tinggi. Maka untuk peningkatan kualitas layanan dijalur data dengan cara penggantian akses jaringan kefiber optik. Teknologi serat optik mempunyai laju data yang bebas dari inferensi dan akses jalur data yang cepat.

PT Telkom Akses Batam adalah perusahaan yang bergerak dalam bisnis penyediaan layanan konstruksi dan pengelolaan infrastruktur jaringan yang selalu memenuhi kebutuhan pelanggannya dengan akses jaringan lokal tembaga berupaya membangun jaringan berkecepatan tinggi berbasis serat optik. Salah satu teknologinya adalah menggunakan FTTH (Fiber to The Home). Fiber to The Home 
menggunakan koneksi internet broadband yang memakai kabel serat optik untuk pengguna personal atau rumahan. Pembangunan jaringan FTTH menggunakan teknologi GPON (Gigabit Passive Optical Network) karena sudah mendukung aplikasi triple play yang melayani 3 layanan seperti suara, video, dan juga data dalam satu alat.

Sistem komunikasi serat optik adalah sistem komunikasi yang dalam pengiriman dan penerimaan sinyal menggunakan sumber optik dan detektor optik dengan panjang gelombang sinar inframerah antara $850 \mathrm{~nm}-1550 \mathrm{~nm}$ (frekuensi $0,035 \mathrm{THz}-0,019 \mathrm{THz}$ ) yang dilakukan pada media transmisi serat optik [1]. Serat optik tipe single mode step index mempunyai redaman yang relatif kecil pada panjang gelombang 1310 dan $1550 \mathrm{~nm}$ serta kapasitas besar identik dengan bandwidth yang lebar [2]. Bandwith yang lebar dibutuhkan untuk transfer informasi baik internet, e-comerce, e-mail, electronic documentation transfer, vidio dan mobile telephony. GPON memiliki efisiensi bandwidth yang lebih baik karena sangat cocok diterapkan dalam membangun jaringan FTTH, dimana pelanggannya membutuhkan bandwidth yang cukup besar [3].

Masyeba Bukit Mas adalah salah satu perumahan di Batam yang dipilih untuk pembangunan jaringan FTTH karena masih menggunakan jaringan lama yang memiliki jalur akses data yang terbatas. Banyak laporan dari masyarakat tentang layanan internet jaringan lama yang kurang memuaskan. Misalnya, jaringan yang sering hilang signal, bandwidth yang lemah, browsing yang melambat, dan mengalami jaringan putus tiba-tiba bahkan hilang sama sekali. Hilangnya jaringan akses pada jaringan lama seolah-olah menjadi rutinitas yang harus pelanggan terima.

Masalah yang dihadapi PT. Telkom yaitu bayaknya keluhan pelanggan tentang kecepatan yang dihasilkan dari jaringan saat ini yaitu jaringan kabel tembaga khususnya masyarakat perumahan Masyeba Bukit Mas di Kota Batam. Keluhannya berupa jaringan layanan internet jaringan tembaga sangat lambat, sering signal hilang, bandwidth yang lemah, browsing yang melambat, dan mengalami jaringan putus tiba-tiba bahkan hilang sama sekali. Berdasarkan observasi maka disimpulkan bahwa teknologi jaringan lama tidak mampu lagi untuk memenuhi kebutuhan pelanggan, disamping itu sudah ada teknologi terbaru yang muncul sebagai teknologi yang mumpuni yang sedang diterapkan oleh PT. Telkom.

Berdasarkan masalah diatas maka solusi yang ditawarkan adalah mengimplementasikan jaringan fiber optik mulai dari sentral sampai kepelanggan. Kegiatan mplementasi jaringan FTTH diantaranya membuat gambar skema jalur pentransmisian jaringan FTTH, menentukan link power budget dan QoS sebagai parameter yang digunakan untuk mengukur kualitas jaringan FTTH.

\subsection{Jaringan Komputer}

Jaringan komputer adalah kumpulan dua atau lebih komputer yang saling berhubungan satu sama lain untuk melakukan komunikasi data dengan menggunakan protokol komunikasi melalui media komunikasi (kabel atau nirkabel), sehingga komputer-komputer tersebut dapat saling berbagi informasi, data, program-program, dan penggunaan perangkat keras secara bersama. Jenis jaringan komputer terdiri dari [4]:

1) Jaringan Nirkabel: Jaringan nirkabel adalah satu jenis jaringan yang media transmisinya menggunakan wireless frekuensi radio, yang mana sinyal-sinyal yang dikirim menyebar keseluruh client dari hasil broadcast link suatu alat yang sering disebut dengan acces point [5].

2) Jaringan Kabel: Jaringan kabel LAN merupakan jaringan yang terbentuk dari gabungan beberapa komputer yang saling tersambung melalui saluran fisik (kabel). Dimana jaringan LAN menggunakan empat tipe kabel yaitu Coaxial, UTP, STP, dan Fiber Optik.

\subsection{Quality of Service (Qos)}

Quality of service (QoS) menunjukkan kemampuan sebuah jaringan dalam menyediakan layanan yang lebih baik bagi trafik yang melewatinya [6]. Kemampuan QoS merupakan kumpulan dari beberapa parameter besaran teknis, yaitu [7]:

1) Throughput yaitu kecepatan (rate) transfer data efektif, yang diukur dalam bit/s. Throughput merupakan jumlah total kedatangan paket yang sukses yang diamati pada destinasi selama interval waktu tertentu dibagi oleh durasi interval waktu tersebut.

2) Delay adalah waktu tunda suatu paket yang diakibatkan oleh proses transmisi dari satu titik ke titik lain yang menjadi tujuannya.

3) Jitter merupakan variasi dari delay end-to-end. Level yang tinggi pada jitter dalam aplikasi berbasis user datagram protocol $(U D P)$ merupakan situasi yang tidak dapat diterima dimana aplikasi merupakan aplikasi real time, seperti sinyal audio dan video.

4) Packet loss didefinisikan sebagai kegagalan transmisi paket IP mencapai tujuannya. Kegagalan paket tersebut untuk mencapai tujuan dapat disebabkan oleh beberapa kemungkinan yaitu terjadinya overload trafik didalam jaringan, tabrakan (congestion) dalam jaringan, error yang 
terjadi pada media fisik, kegagalan yang terjadi pada sisi penerima antara lain bisa disebabkan karena overflow yang terjadi pada buffer.

\subsection{Jaringan FTTX}

Secara umum sistem jaringan FTTX yaitu jaringan lokal bebasis fiber optik, dimana dalam sistem ini terdapat dua buah atau lebih perangkat aktif, di mana satu perangkat akif yang di pasang disisi sentral yang berfungsi untuk mengubah sinyal elektrik menjadi sinyal optik, dan satu perangkat lagi dipasang didekat pelanggan atau dilokasi pelanggan itu sendiri yang berfungsi mengubah kembali dari sinyal optik menjadi sinyal elektrik, dimana lokasi perangkat aktif disisi pelanggan disebut juga titik konversi optik (TKO), dengan demikian TKO adalah batas akhir kabel optik ke arah pelanggan yang berfungsi sebagai lokasi konversi sinyal optik ke sinyal elektrik [8]. Perbedaan letak TKO menimbulkan modus aplikasi FTTX yang berbeda-beda berupa:

1) Fiber to The Building, TKO terletak didalam gedung dan biasanya terletak pada ruang telekomunikasi di basement atau tersebar di beberapa lantai, terminal pelanggan dihubungkan dengan TKO melalui kabel tembaga indoor, FTTB dapat dianalogikan dengan daerah catu langsung atau terminal blok (TB) pada jaringan kabel tembaga.

2) Fiber to The Zone, TKO terletak disuatu tempat di luar bangunan, biasanya berupa cabinet yang di tempatkan di pinggir jalan sebagai mana biasanya, terminal pelanggan dihubungkan dengan TKO melalui kabel tembaga hingga beberapa kilometer.

3) Fiber to The Curb, TKO terletak disuatu tempat di luar bangunan, baik di dalam cabinet, di atas tiang maupun di man hole, terminal pelanggan dihubungkan dengan TKO melaui kabel tembaga hingga beberapa ratus meter saja, FTTC dapat dianalogikan sebagai pengganti Distribusi Point (DP).

4) Fiber to The Tower, TKO terletak didalam shelter dari pada tower, terminal equipment system GSM / CDMA dihubungkan dengan TKO melalui kabel tembaga indoor hingga beberapa meter saja, jaringan kabel FO yang mencatu tower. FTTH adalah jaringan yang terdiri dari perangkat aktif baik OLT (Optical Line Termination) dan ONT (Optical Network Termination) yang di hubungkan dengan media fiber optik dan perangkat pendukung lainnya atau yang di sebut ODN (Optical Dsitribution Network) seperti ODC, ODP, Splitter, ODF.

5) Fiber to The Home, TKO terletak didalam rumah pelanggan, terminal pelanggan dihubungkan dengan TKO melalui kabel tembaga indoor hingga beberapa meter saja. Perkembangan teknologi ini tidak terlepas dari kemajuan perkembangan tenologi serat optic yang dapat menggantikan penggunaan kabel konvensional. Dan juga di dorong untuk mendapatkan layananan yang di kenal dengan Triple Play Services yaitu layanan akan akses internet yang cepat, suara (jaringan telepon, PSTN) dan video (TV Kabel) dalam satu infrastruktur pada unit pelanggan.

\subsection{Gigabit Passive Optical Network (GPON)}

Prisip kerja dari GPON yaitu ketika data atau sinyal dikirimkan dari OLT, maka ada bagian yang bernama splitter yang berfungsi untuk memungkinkan serat optik tunggal dapat mengirim ke berbagai ONT. Untuk ONT sendiri akan memberikan data-data dan sinyal yang diinginkan oleh user.

Konfigurasi GPON terdiri dari 3 bagian utama yaitu:

1) OLT (Optical Line Terminal) adalah perangkat utama terpasang di sisi sentral

2) ODN (Optical Data Network) adalah perangkat fiber optic meliputi ODF, ODC, ODP, Splitter.

3) ONT (Optical Network Terminal) adalah perangkat aktif disisi pelanggan.

GPON mampu memberikan layanan Triple Play yaitu voice, data dan video [8].

1) Voice: Bila kita memberikan layanan voice via jaringan FTTH GPON maka layanan voice dapat diberikan melalui

a. POTS port pada ONT dengan antar muka FXS (RJ11)

b. Dengan POTS ini maka telepon yang digunakan berupa telepon analog (telepon biasa)

c. SIP /H.248 Phone (RJ45)

d. Dengan protocol SIP/H.248 maka terminal telepon yang digunakan berupa IP phone. Interface yang digunakan antara IP phone dan ONT berupa RJ45.

2) Video / IPTV: Untuk layanan video atau IPTV dapat dicapai dengan menggunakan dua opsi. Opsi pertama menggunakan interface RF sedangkan opsi kedua menggunakan interface Ethernet.

3) Data Comm: Untuk layanan komunikasi data, maka interface yang digunakan adalah RJ45. 


\subsection{Tools dan Software Pendukung}

Untuk membantu pengerjaan penelitian ini, peneliti menggunakan beberapa tools dan software, diantaranya:

1) Google Earth

Google Earth merupakan sebuah program globe virtual yang sebenarnya disebut earth viewer dan dibuat oleh Keyhole, Inc [9]. Program ini memetakan bumi dari superimposisi gambar yang dikumpulkan dari pemetaan satelit, fotografi udara dan globe GIS (sistem informasi geografis) tiga dimensi.

2) Optical Power Meter (OPM)

OPM digunakan untuk mengukur daya yang dipancarkan yaitu mengukur redaman dari fiber optik yang tengah berjalan [10]. Cara kerja OPM dapat dilihat dari nilai daya input yang di pancarkan dan nilai daya output yang di terima oleh OPM dengan satuan $\mathrm{dBm}$ (Desibell milliwatt) karena data yang di ambil mewakili satuan daya dalam satuan algoritmik.

3) Axence netTool

Merupakan tool yang yang dipakai untuk menganalisa performance suatu jaringan untuk menentukan bandwidth, packet los, delay, dan jitter. Axence netTools adalah satu set sepuluh alat-alat praktis untuk scanning jaringan dan monitoring yang populer di seluruh dunia. Software ini dirancang baik untuk rumah dan penggunaan komersial.

\subsection{Kerangka Pemikiran}

Setelah sintesa atau kesimpulan sementara dapat dirumuskan maka selanjutnya disusun kerangka berfikir [11]. Adapun kerangka pemikiran penelitian ini tertera pada gambar 1 dibawah ini:

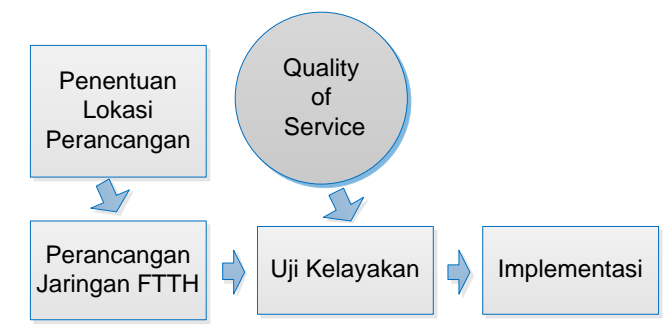

Gambar 1. Kerangka Pemikiran

\section{METODE PENELITIAN}

\subsection{Desain Penelitian}

Desain penelitian adalah cara ilmiah untuk mendapatkan data yang valid dengan tujuan dapat ditemukan, dikembangkan, dan dibuktikan, suatu pengetahuan tertentu sehingga pada gilirannya dapat digunakan untuk memahami, memecahkan dan mengantisipasi masalah [11]. Pada gambar 2 merupakan desain penelitian.

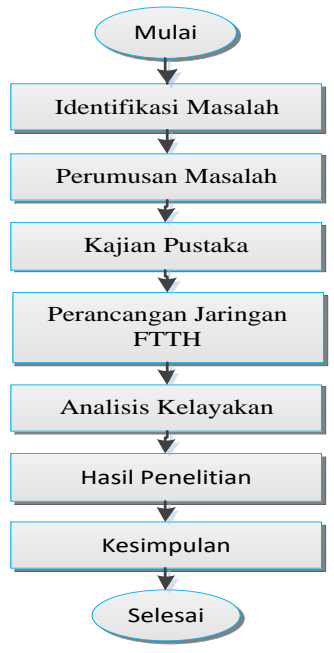

Gambar 2. Desain Penelitian 


\subsection{Perancangan Awal}

Berikut pada gambar 3 dibawah ini adalah rancangan awal jaringan FTTH yang direncanakan.

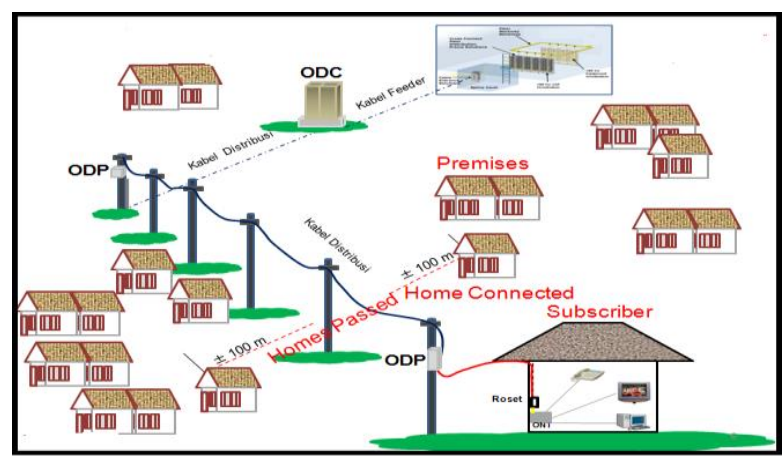

Gambar 3. Konfigurasi Umum FTTH

\subsection{Penentuan Perangkat}

Pada penelitian ini perangkat jaringan yang dibutuhkan pada perancangan jaringan yang akan dibangun sebagai berikut:

1) Perangkat Optical Line Terminal (OLT): Perangkat OLT merupakan perangkat aktif yang terletak di STO yang berfungsi mengubah sinyal elektrik menjadi sinyal optik [8].

2) Perangkat Optical Distribution Point (ODC): Suatu tool pasif yang yang dipasang dibagian luar STO diletakkan di lapangan (outdoor) dan juga diletakkan dibagian dalam ruangan/di MDF Gedung HRB (indoor), yang mempunyai kegunaan antara lain:
a. point terminasi ujung kabel feeder dan pangkal kabel distribusi
b. point distribusi transmisi berupa kabel dari kapasitas besar (feeder) menjadi beberapa kabel yang kapasitasnya lebih kecil lagi (distribusi) untuk flexsibilitas.
c. Media atau tempat spliter.
d. Media penyambungan.

3) Passive Splitter: Passive Splitter (PS) adalah suatu tool pasif dimana kegunaannya untuk membagi informasi sinyal optik (gelombang cahaya), kapasitas distribusi dari passive splitter terdiri dari berbagai jenis yaitu 1:2, 1:4, 1:8, 1:16, 1:32, dan 1:64. Dalam menggunakan passive splitter perlu diperhatikan karena setiap splitter mempunyai redaman yang berbeda untuk perhitungan Link Power Budget. Redaman dari masing-masing splitter dapat dilihat pada tabel 1 berikut:

Tabel 1. Passive splitter

\begin{tabular}{ccc}
\hline Network Elemen & Batasan & Ukuran \\
\hline $1: 2$ & Maximal & $3,70 \mathrm{~dB}$ \\
$1: 4$ & Maximal & $7,25 \mathrm{~dB}$ \\
$1: 8$ & Maximal & $10,38 \mathrm{~dB}$ \\
$1: 16$ & Maximal & $14,10 \mathrm{~dB}$ \\
$1: 32$ & Maximal & $17,45 \mathrm{~dB}$ \\
\hline
\end{tabular}

4) Perangkat Optical Distribution Point (ODP): perangkat passive yang juga dipasang diluar STO, dapat dipasang diluar ruangan maupun didalam ruangan. Jenis ODP ada 3 yaitu ODP Wall, ODP Pedestal, dan ODP Closure. Adapun fungsi ODP sebagai berikut:

a. Sebagai titik terminasi ujung kabel distribusi dan titik tambat awal.

b. Sebagai titik distribusi kabel distribusi menjadi beberapa saluran kabel drop.

c. Tempat Splitter.

d. Tempat penyambungan kabel distribusi dan tempat terminasi kabel drop.

Dilihat dari lokasi tempat pemasangan ODP dapat di bagi menjadi 3 yaitu;

a. ODP Wall/ On Pole, ODP ini dipasang di dinding atau diatas tiang dalam hal ini adalah pada instalasi kabel drop atas tanah (aerial).

b. ODP Pedestal, jenis ODP ini dipasang diatas permukaan tanah, dan digunakan untuk pemasangan kabel drop bawah tanah dengan pelindung pipa pvc $2 \mathrm{~cm}$.

c. ODP Closure, jenis ini sangat fleksibel bisa diinstalasi didekat tiang, atau dipasang diantara dua tiang (pada kabel distribusi aerial) 
5) Kabel Fiber Optic

a. Feeder: Merupakan kabel fiber optic yang mempunyai fungsi untuk menyalurkan informasi yang berupa sinyal optik hasil konversi perangkat OLT, biasanya menggunakan kabel Single Mode tipe G652D

b. Distribusi: Merupakan kabel fiber optic yang mempunyai fungsi untuk meneruskan informasi yang berupa sinyal optik mulai dari ODC sampai ke ODP dan tetap menggunakan kabel fiber optic Single Mode tipe G652D dan jenis instalasinya sama dengan feeder

c. Kode warna isolasi coating: Untuk lebih jelasnya kode warna dapat dilihat pada gambar 4 dan gambar 5 dibawah ini:

\begin{tabular}{|c|c|c|c|c|c|c|c|c|c|c|c|c|}
\hline $\begin{array}{c}\text { No Urut } \\
\text { Loose Tube }\end{array}$ & 1 & 2 & 3 & 4 & 5 & 6 & 7 & 8 & 9 & 10 & 11 & 12 \\
\hline Warna & 름 & 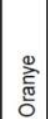 & 烝 & \begin{tabular}{|l|}
$\frac{\pi}{\pi}$ \\
$\frac{\vec{j}}{0}$
\end{tabular} & 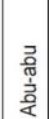 & \begin{tabular}{|l}
$\frac{c}{5}$ \\
\multirow{2}{*}{}
\end{tabular} & \begin{tabular}{|l|}
$\frac{c}{\pi}$ \\
$\frac{\pi}{2}$ \\
$\frac{\pi}{2}$
\end{tabular} & 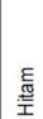 & 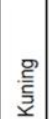 & 兮 & 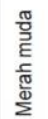 & 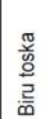 \\
\hline
\end{tabular}

Gambar 4. Warna Isolasi Coating (Dalam)

\begin{tabular}{|c|c|c|c|c|c|c|c|c|c|c|c|c|c|c|}
\hline $\begin{array}{c}\text { No Urut } \\
\text { Loose } \\
\text { Tube }\end{array}$ & 1 & 2 & 3 & 4 & 5 & 6 & 7 & 8 & 9 & 10 & 11 & 12 & 13 & 14 \\
\hline Warna & $\frac{2}{0}$ & 离 & 㞼 & $\frac{\pi}{\frac{\pi}{0}}$ & 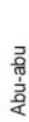 & 亭 & 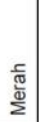 & 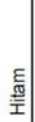 & 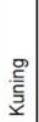 & $\begin{array}{l}\text { 구 } \\
\text { ড }\end{array}$ & $\begin{array}{l}\frac{\pi}{0} \\
\frac{1}{E} \\
\frac{\pi}{\pi} \\
\frac{\pi}{2} \\
\sum\end{array}$ & $\frac{\pi}{\frac{\pi}{0}}$ & 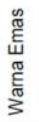 & 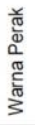 \\
\hline
\end{tabular}

Gambar 5. Warna Isolasi Coating (Luar) (Sumber: Telkom Akses)

6) Perangkat Optical Termination Premies (OTP): OTP merupakan perangkat pasif yang dipasang disisi pelanggan yang mempunyai fungsi sebagai titik terminasi atau titik tambat akhir dari kabel outdoor dan indoor.

7) Perangkat Optical Network Terminal (ONT): ONT merupakan perangkat aktif yang dipasang disisi pelanggan yang berfungsi mengubah sinyal optic menjadi sinyal elektrik dan mempunyai keluaran dengan layanan triple play.

8) Perangkat Konektor: konektor merupakan perangkat yang dipasang di ujung dari core optic baik pada kabel feeder, distribusi drop maupun indoor sebagai penghubungnya.

9) Optical Indoor Outlet (Roset): Roset merupakan perangkat pasif yang diletakan didalam rumah pelanggan, yang menjadi titik terminasi akhir dari kabel indoor fiber optik, kapasitas roset biasanya 1 atau 2 port.

10) Pigtail: Seutas serat optik yang pendek untuk menghubungkan perangkat dengan kabel optik, dilengkapi satu konektor pada salah satu ujungnya.

11) Patch - cord: Penyambung / kabel interkoneksi, biasanya dengan konektor yang sudah terpasang di kedua ujungnya, digunakan untuk menghubungkan dua perangkat

\subsection{Analisis Kelayakan}

Analisis kelayakan pada penelitian ini mengugunakan metode perhitungan. Parameter yang dihitung adalah Link Power Budget dan Power Margin untuk uji kelayakan hasil perancangan. Untuk mengantisipasi kebutuhan operasional maka dalam desain FTTH harus disediakan margin antara 2 sampai $3 \mathrm{~dB}$, sehingga dalam merencanakan pembangunan maksimum redaman antara 25 sampai $26 \mathrm{~dB}$, kabel $0,35 \mathrm{~dB} / \mathrm{km}$, splicing $0,1 \mathrm{~dB}$, connector los $0,25 \mathrm{~dB}[8]$.

Link Power Budget, Untuk perhitungan Link Power Budget dapat dihitung dengan persamaan:

$$
a_{\text {tot }}=L \cdot a_{\text {semat }}+\mathrm{Nc} \cdot a_{\mathrm{ge}}+\mathrm{Ns} \cdot a_{\mathrm{g}}+\mathrm{Sp}+\mathrm{RI}
$$

Bentuk persamaan untuk perhitungan margin daya adalah:

$M=(P t-\operatorname{Pr})-a_{\text {total }}-S M$

Keterangan

Pt: Daya keluaran sumber optik (dBm), Pr: Sensitivitas daya maksimun detector $(\mathrm{dBm}), \mathrm{SM}$ : Safety margin, berkisar 2-3 dB, L: Panjang Serat Optik (KM), Ns: Jumlah sambungan, Nc: Jumlah konektor, Sp: Redaman Splitter, RI: Redaman Instalasi (dB/Km), $a_{\text {tot }}$ : Redaman Total Sistem (dB), 
$a_{g}$ : Redaman Konektor (dB/buah), $a_{g}$ : Redaman Sambungan (dB/sambungan), $a_{\text {serat }}$ : Redaman Serat Optik (dB/Km)

Margin daya disaratkan harus memiliki nilai lebih dari 0 (nol), margin daya adalah daya yang dari loss selama proses pentransmisian, pengurangan dengan nilai safety margin dan pengurangan dengan nilai sensitifitas receiver.

\subsection{Pengukuran Qos}

Berikut kategori-kategori standar dalam pengukuran parameter QoS [12]:

1) Bandwidth: Sebuah bandwidth dikatakan bagus jika memilih nilai upload dan download yang tinggi. Besarnya dapat diklasifikasikan pada tabel 2 sebagai berikut:

Tabel 2. Kategori bandwidth

\begin{tabular}{lllll}
\hline No & Kategori & Upload & Download & Indeks \\
\hline 1 & Sangat Bagus & $>1,00 \mathrm{Mb} / \mathrm{s}$ & $>4,00 \mathrm{Mb} / \mathrm{s}$ & 4 \\
2 & Bagus & $0,60-0,99 \mathrm{Mb} / \mathrm{s}$ & $2,00-3,99 \mathrm{Mb} / \mathrm{s}$ & 3 \\
3 & Sedang & $0,30-0,59 \mathrm{Mb} / \mathrm{s}$ & $1,00-1,99 \mathrm{Mb} / \mathrm{s}$ & 2 \\
4 & Jelek & $<0,3 \mathrm{Mb} / \mathrm{s}$ & $<1,00 \mathrm{Mb} / \mathrm{s}$ & 1 \\
\hline
\end{tabular}

2) Packet Loss: Berdasarkan standar dari Telecommunications and Internet Protocol Harmonization Over Networks (TIPHON) packet loss dikategorikan sesuai dengan tabel 3 sebagai berikut:

Tabel 3. Kategori packet loss

\begin{tabular}{llll}
\hline No & Kategori & Latency & Indeks \\
\hline 1 & Sangat Bagus & $0 \%$ & 4 \\
2 & Bagus & $1-3 \%$ & 3 \\
3 & Sedang & $4-15 \%$ & 2 \\
4 & Jelek & $16-25 \%$ & 1 \\
\hline
\end{tabular}

3) Delay: adalah waktu yang dibutuhkan data untuk menempuh jarak dari asal ke tujuan. Throughput: Kecepatan (rate) transfer data efektif, yang diukur dalam bps Throughput: Kecepatan (rate) transfer data efektif, yang diukur dalam bps. Besarnya dapat diklasifikasikan pada tabel 4 sebagai berikut

Tabel 4. Delay, Jitter, Throughput

\begin{tabular}{llll}
\hline Kategori & Throughput & Jitter & Throughput \\
\hline Sangat Bagus & $100 \%$ & $0 \mathrm{~ms}$ & $100 \%$ \\
Bagus & $75 \%$ & 0 sampai $75 \mathrm{~ms}$ & $75 \%$ \\
Sedang & $50 \%$ & 76 sampai $125 \mathrm{~ms}$ & $50 \%$ \\
Jelek & $<25 \%$ & 125 sampai $225 \mathrm{~ms}$ & $<25 \%$ \\
\hline
\end{tabular}

\section{HASIL DAN PEMBAHASAN}

Pada penelitian ini perancangan awal jaringan dimulai dengan penentuan lokasi. Perumahan Masyeba Bukit Mas dipilih sebagai lokasi penelitian. STO (Sentral Telepon Otomatic) Bukit Dangas berada sekitar 8,57 Km dari perumahan Masyeba Bukit Mas, ODC berada 0,58 km dari ODP terjauh, dan ODP berada $0,15 \mathrm{~km}$ dari ONT terjauh. Peneliti melakukan survei kelokasi untuk mengambil koordinat yang akan digunakan untuk pembuatan desain gambar pembangunan jaringan FTTH yang akan diiplementasikan pada aplikasi Google Earth. Berikut hasil koordinat di tunjukan pada tabel 7, deskripsi pada gambar 6 dan 7 sebagai berikut:

Tabel 5. Koordinat posisi perangkat

\begin{tabular}{ll}
\hline Perangkat & Koordinat \\
\hline Optical Line Terminal (STO BDS) & $1.123862,103.941688$ \\
Optical Distribution Point (BDS FAA) & $1.115758,103.984093$ \\
Optical Distribution Point (BDS FAA 58) & $1.116380,103.985255$ \\
Optical Distribution Point (BDS FAA 59) & $1.116384,103.985610$ \\
Optical Distribution Point (BDS FAA 60) & $1.116326,103.986481$ \\
Optical Distribution Point (BDS FAA 61) & $1.116011,103.987006$ \\
Optical Distribution Point (BDS FAA 62) & $1.115760,103.986350$ \\
Optical Distribution Point (BDS FAA 63) & $1.115747,103.985549$ \\
\hline
\end{tabular}




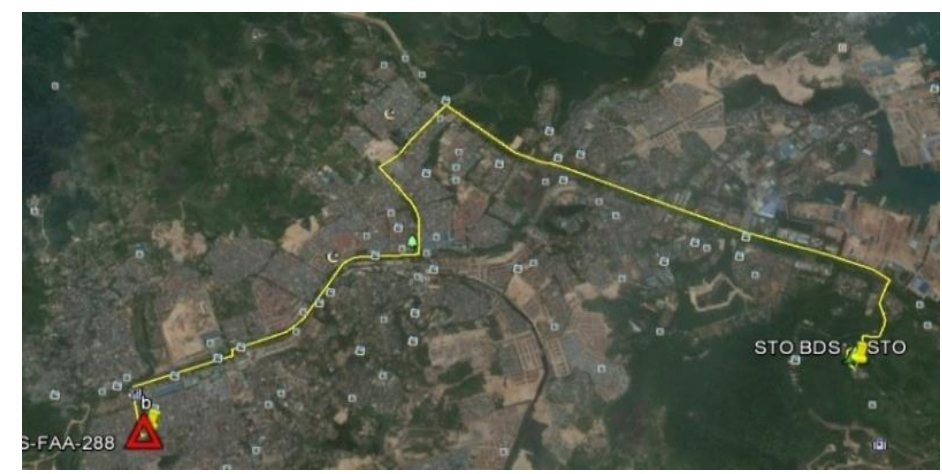

\section{Gambar 6. Fiber Optic STO Bukit Dangas-ODC Masyeba Bukit Mas}

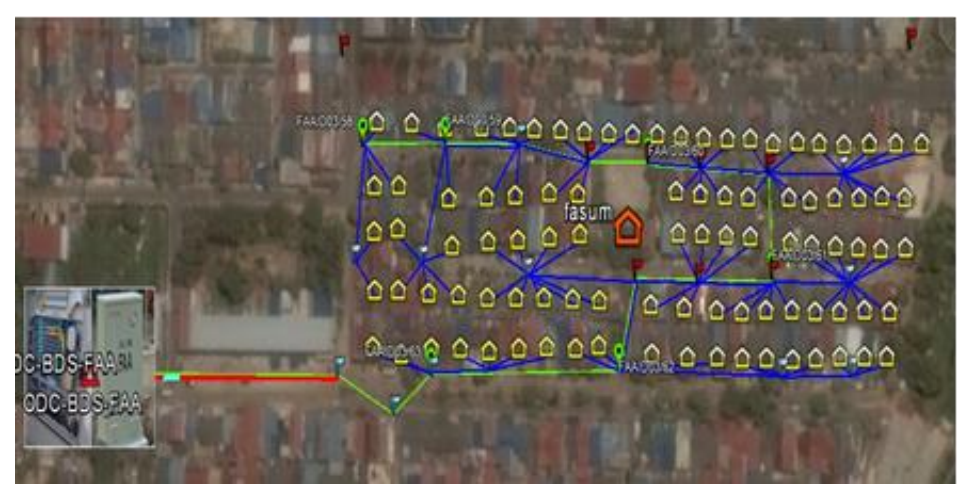

Gambar 7. Fiber Optik ODC-ODP-ONT

\subsection{Uji Kelayakan}

Setelah melakukan perancangan jaringan FTTH menggunakan teknologi GPON, untuk mengetahui kelayakan sistem dan batasan redaman total yang diijinkan antara daya keluaran pemancar dan juga pada sensitivitas penerima maka dianalisis menggunakan parameter Power Link Budget dan Margin Daya. Margin daya disaratkan harus memiliki nilai lebih dari 0 (nol), margin daya adalah daya yang dari loss selauma proses pentransmisian, pengurangan dengan nilai safety margin dan pengurangan dengan nilai sensitifitas receiver.

Data-data yang akan digunakan untuk perhitungan antara lain:
1) Sensitivitas detector (OLT)
: $-28 \mathrm{dBm}$
2) Redaman Serat Optik G.652 (1310/1490) : : $(0,35 / 0,28) \mathrm{dB} / \mathrm{Km}$
3) Redaman Splice
4) Konektor
: $0,05 \mathrm{~dB} /$ Splice
5) Passive 1:4
$: 0,2 \mathrm{~dB}$
6) Passive 1:8
: 7,25 dB
: $10,38 \mathrm{~dB}$
7) Jumlah Sambungan
$: 4$ buah
8) Jumlah Konektor (sambungan)
: 4 buah
9) Redaman Instalasi
: 2,86497 dB
10) SM
$: 6 \mathrm{~dB}$

Perhitungan akan dilakukan dengan cara menghitung jarak terjauh dari STO Bukit Dangas menuju ONT terjauh pada perumahan Masyeba Bukit Mas karena jika ONT terjauh memenuhi kelayakan maka ONT terdekat pasti akan memenuhi kelayakan batasan redaman total yang diijinkan antara daya keluaran pemancar dan sensitivitas penerima. Perhitungan dapat diuraikan sebagai berikut: Jarak STO BDS ODC $=8,57 \mathrm{Km}$, Jarak ODC-ODP Terjauh= 0,58 Km, Jarak ODP-ONT Terjauh= 0,15 Km.

Perhitungan Downlink dengan menggunakan persamaan 1, maka:

$$
\begin{aligned}
a_{\text {tot }} & =(8,57 * 0,28)+(0,58 * 0,28)+(0,15 * 0,28)+(4 * 0,2)+(4 * 0,05)+(7,25+10,38)+2,86497 \\
& =2,3996+0,1624+0,042+0,8+0,2+17,63+2,86497 \\
a_{\text {tot }} & =24,09897 \mathrm{~dB}
\end{aligned}
$$

Sehingga untuk perhitungan Margin daya dengan menggunakan persamaan 2 adalah:

$\operatorname{Pr}=5-24,09897-6$

$\mathrm{M}=(\mathrm{Pt}-\operatorname{Pr}($ Sensitivitas $))-a_{\text {tot }}-\mathrm{SM}$
$\mathrm{Pr}=-25,09897 \mathrm{dBm}$

$\mathrm{M}=(5-(-28))-24,09897-6$ 


$$
\mathrm{M}=(5+28)-24,09897-6 \quad \mathrm{M}=3,90103 \mathrm{dBm}
$$

Nilai M yang diperoleh dari hasil perhitungan downlink ternyata menghasilkan nilai yang masih berada diatas 0 (nol) dB. Hal ini mengindikasikan bahwa link diatas memenuhi kelayakan link power budget.

Perhitungan Uplink dengan menggunakan persamaan 1, maka:

$$
\begin{aligned}
a_{\text {tot }} & =(8,57 * 0,35)+(0,58 * 0,35)+(0,15 * 0,35)+(4 * 0,2)+(4 * 0,05)+(7,25+10,38)+2,86497 \\
& =2,9995+0,203+0,0525+0,8+0,2+17,63+2,86497 \\
& =24,74997 \mathrm{~dB}
\end{aligned}
$$

Sehingga untuk perhitungan Margin daya dengan menggunakan persamaan 2 adalah:

$$
\begin{array}{ll}
\operatorname{Pr}=5-24,74997-3 & P r=-25,74997 \mathrm{dBm} \\
\mathrm{M}=(\operatorname{Pt}-\operatorname{Pr}(\text { Sensitivitas }))-a_{\text {tot }}-\mathrm{SM} & \mathrm{M}=(5-(-28))-24,74997-3 \\
\mathrm{M}=(5+28)-24,74997-3 & \mathrm{M}=3,25003 \mathrm{dBm}
\end{array}
$$

Nilai M yang diperoleh dari hasil perhitungan Uplink ternyata menghasilkan nilai yang masih berada diatas 0 (nol) dB. Hal ini mengindikasikan bahwa link diatas memenuhi kelayakan link power budget. Selanjutnya, melakukan konfigurasi yaitu proses pengiriman paket internet dengan menggunakan aplikasi my indihome yang merupakan aplikasi internal dari Telkom.

\subsection{Pengukuran QoS}

Pengukuran Quality of Service dilakukan dengan cara memilih secara acak 6 pelanggan indihome kabel fiber optic. Pada tabel 6 adalah hasil rekapitulasi pengukuran parameter QoS indihome kabel fiber optic.

Keterangan dari tabel 6 adalah sebagai berikut: Pengguna 1. Anwar Hidayat (Blok E No7) 2. Ryan Kurniawan (Blok A No 12) 3. Fri Dona (Blok F No 8) 4. Endang Monalisa (Blok C No 12A) 5. Andi Irawan bin Sunardi (Blok H No 9) 6. Andi Budiardi (Blok D No 8). a menyatakan website

\begin{tabular}{|c|c|c|c|c|c|c|c|c|c|c|c|c|c|c|c|c|c|c|c|}
\hline \multirow{2}{*}{ User } & \multirow{2}{*}{ Web } & \multicolumn{4}{|c|}{ Paket } & \multicolumn{3}{|c|}{ Band (kbps) } & \multicolumn{4}{|c|}{ Paket } & \multicolumn{3}{|c|}{$\mathrm{D}(\mathrm{m} / \mathrm{s})$} & \multicolumn{4}{|c|}{ Packet } \\
\hline & & $\mathbf{S}$ & $\mathbf{R}$ & $\mathbf{L}$ & $\%$ & Max & Min & Avrg & $\mathbf{S}$ & $\mathbf{R}$ & $\mathbf{L}$ & $\%$ & Max & Min & Avrg & $\mathbf{S}$ & $\mathbf{R}$ & $\mathbf{R}(\%)$ & L (\%) \\
\hline \multirow[t]{3}{*}{1} & $\mathrm{a}$ & 29 & 29 & 0 & 0 & 2960 & 31 & 1484 & 29 & 29 & 0 & 0 & 26 & 5 & 10 & 22 & 22 & $100 \%$ & $0 \%$ \\
\hline & $b$ & 61 & 59 & 2 & 0,03 & 3077 & 32 & 1914 & 61 & 59 & 2 & 0,03 & 30 & 5 & 9 & 22 & 22 & $100 \%$ & $0 \%$ \\
\hline & $\mathrm{c}$ & 37 & 32 & 5 & 0,14 & 2865 & 19 & 1760 & 37 & 32 & 5 & 0,14 & 695 & 6 & 63 & 19 & 19 & $100 \%$ & $0 \%$ \\
\hline \multirow[t]{3}{*}{2} & $\mathrm{a}$ & 19 & 19 & 0 & 0 & 2939 & 1111 & 2260 & 19 & 19 & 0 & 0 & 268 & 6 & 20 & 26 & 26 & $100 \%$ & $0 \%$ \\
\hline & $b$ & 21 & 21 & 0 & 0 & 3154 & 24 & 2295 & 21 & 21 & 0 & 0 & 515 & 5 & 37 & 44 & 41 & $93 \%$ & $7 \%$ \\
\hline & $\mathrm{c}$ & 21 & 21 & 0 & 0 & 2718 & 18 & 1388 & 21 & 21 & 0 & 0 & 283 & 6 & 37 & 23 & 23 & $100 \%$ & $0 \%$ \\
\hline \multirow[t]{3}{*}{3} & $\mathrm{a}$ & 10 & 10 & 0 & 0 & 2598 & 190 & 1629 & 10 & 10 & 0 & 0 & 86 & 6 & 24 & 18 & 18 & $100 \%$ & $0 \%$ \\
\hline & $b$ & 29 & 29 & 0 & 0 & 3244 & 367 & 1965 & 29 & 29 & 0 & 0 & 771 & 5 & 61 & 40 & 39 & $98 \%$ & $3 \%$ \\
\hline & $\mathrm{c}$ & 27 & 27 & 0 & 0 & 2776 & 494 & 1948 & 27 & 27 & 0 & 0 & 81 & 6 & 16 & 23 & 23 & $100 \%$ & $0 \%$ \\
\hline \multirow[t]{3}{*}{4} & $\mathrm{a}$ & 18 & 18 & 0 & 0 & 2852 & 28 & 1222 & 18 & 18 & 0 & 0 & 518 & 7 & 134 & 17 & 14 & $82 \%$ & $18 \%$ \\
\hline & $b$ & 24 & 23 & 1 & 0,04 & 3026 & 47 & 1304 & 24 & 23 & 1 & 0,04 & 514 & 6 & 128 & 38 & 5 & $13 \%$ & $87 \%$ \\
\hline & $\mathrm{c}$ & 49 & 49 & 0 & 0 & 2785 & 35 & 1255 & 49 & 49 & 0 & 0 & 27 & 6 & 10 & 29 & 29 & $100 \%$ & $0 \%$ \\
\hline \multirow[t]{3}{*}{5} & $\mathrm{a}$ & 49 & 48 & 1 & 0,02 & 2926 & 238 & 2286 & 49 & 48 & 1 & 0,02 & 27 & 6 & 8 & 36 & 36 & $100 \%$ & $0 \%$ \\
\hline & $b$ & 13 & 13 & 0 & 0 & 3240 & 1334 & 2443 & 13 & 13 & 0 & 0 & 15 & 5 & 7 & 22 & 21 & $95 \%$ & $5 \%$ \\
\hline & $\mathrm{c}$ & 32 & 32 & 0 & 0 & 2951 & 890 & 2376 & 32 & 32 & 0 & 0 & 22 & 6 & 9 & 37 & 37 & $100 \%$ & $0 \%$ \\
\hline \multirow[t]{3}{*}{6} & $\mathrm{a}$ & 34 & 32 & 2 & 0,06 & 2840 & 19 & 1007 & 34 & 32 & 2 & 0,06 & 677 & 6 & 82 & 32 & 32 & $100 \%$ & $0 \%$ \\
\hline & $b$ & 59 & 53 & 6 & 0,1 & 3153 & 338 & 2150 & 59 & 53 & 6 & 0,1 & 17 & 5 & 8 & 35 & 35 & $100 \%$ & $0 \%$ \\
\hline & $\mathrm{c}$ & 29 & 29 & 0 & 0 & 2915 & 176 & 2229 & 29 & 29 & 0 & 0 & 142 & 6 & 19 & 42 & 42 & $100 \%$ & $0 \%$ \\
\hline \multicolumn{2}{|c|}{ Tot } & 561 & 544 & 17 & 0,39 & 53019 & 5391 & 32915 & 561 & 544 & 17 & 0,39 & 4714 & 103 & 682 & 525 & 484 & $1681 \%$ & 1,2 \\
\hline \multicolumn{2}{|c|}{ Ave } & 31.3 & 30.2 & 0.9 & $\mathbf{0 , 0 2}$ & 2945.5 & 299.5 & 1828.6 & 31.3 & 30.2 & 0.9 & $2 \%$ & 261,9 & 5.72 & 37.89 & 29,2 & 26,89 & $93 \%$ & $\mathbf{0 , 0 7}$ \\
\hline
\end{tabular}
www.yahoo.com, b menyatakan website www.facebook.com, dan c menyatakan website www.kompasiana.com. S: sent, R: receive, L: loss, Ave: rata-rata, Tot: Total.

Dari hasil penelitian pada perumahan Masyeba Bukit Mas di peroleh hasil rata-rata bandwidth pada jaringan fiber optic saat membuka website yahoo, facebook, dan kompasiana sebesar $1828.6 \mathrm{kbps}$, ratarata packet loss sebesar $0.9 \mathrm{kbps}$, rata-rata delay sebesar 37.89 mili second (ms), rata-rata jitter sebesar 2.81 mili second (ms), rata-rata throughput sebesar 93\% seperti tertera pada tabel 6 dibawah ini:

Tabel 6. Rekapitulasi pengukuran parameter Qos

Berikut pada gambar 8 grafik nilai rata-rata pengukuran QoS jaringan fiber optic dengan jaringan tembaga yaitu jaringan lama, dari grafik tersebut kita dapat membandingkan dengan standar TIPHON, maka bandwidth masuk kedalam kategori sangat bagus yaitu $1828.6 \mathrm{kbps}$, packet loss sangat bagus yaitu $0.9 \mathrm{kbps}$, delay sangat bagus yaitu $<150 \mathrm{~ms}$, jitter bagus yaitu $2.81 \mathrm{~ms}$ dan throughput bagus yaitu $93 \%$. 


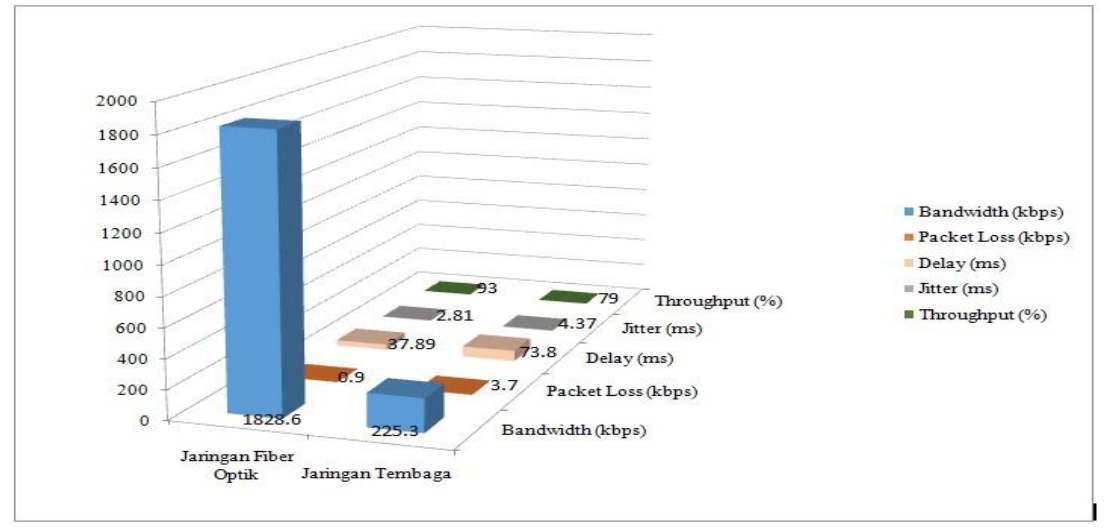

Gambar 8. Grafik Rara-rata Pengukuran QoS

\section{KESIMPULAN}

Berdasarkan hasil pengujian yang telah dilakukan pada penelitian ini, maka dapat ditarik kesimpulan sebagai berikut:

1) Perhitungan uji kelayakan jaringan FTTH dengan teknologi GPON, kelayakan sistem untuk Link Power Budget didapatkan redaman total pada jarak terjauh untuk downlink sebesar - 25,09897 $\mathrm{dBm}$ dan - 25,74997dBm untuk uplink. Hal ini masih dibawah redaman yang dikeluarkan pihak Telkom Akses yaitu maksimal redaman sebesar $-28 \mathrm{dBm}$.

2) Kualitas jaringan Wifi jaringan fiber optik lebih baik dari jaringan tembaga. Pengujian ini dilihat dari hasil rata-rata QoS pada saat membuka website yahoo, facebook, dan kompasiana di jaringan fiber optik mendapatkan bandwidth sebesar $1828.6 \mathrm{kbps}$, packet loss sebesar $0.9 \mathrm{kbps}$, delay sebesar $37.89 \mathrm{~ms}$, jitter sebesar $2.81 \mathrm{~ms}$ dan throughput sebesar $0.93 \%$. Pada jaringan speedy tembaga mendapatkan bandwidth sebesar 225.3kbps, packet loss sebesar $3.7 \mathrm{kbps}$, delay sebesar $73.8 \mathrm{~ms}$, jitter sebesar $4.37 \mathrm{~ms}$ dan throughput sebesar $0.79 \%$.

3) Implementasi jaringan FTTH dengan teknologi GPON dapat menstabilkan koneksi jaringan internet. Dari nilai yang didapatkan, maka bandwidth, packet los, delay, jitter, throughput menjadi factor yang sangat diperlukan agar kualitas jaringan lebih baik.

\section{DAFTAR PUSTAKA}

[1] Hikmaturokhman, A. 2014. "Defitri. Analisa dan Perencanaan Fiber to The Home (FTTH) pada survey Homepass STO Solo Di Area Klaten Selatan”. Pros Semin Nas Apl Sains Teknol. 3(November):63-70.

[2] Danaryani S, Syamsul Y, Krisnadi I. 2015. "Studi Perancangan Jaringan Komunikasi Serat Optik Dwdm L Band dengan Penguat Optikal Edfa". SETRUM. 4(2):16-20.

[3] Dermawan B, Santoso I, Prakoso T. (2016) "Analisis Jaringan Ftth (Fiber to The Home) Berteknologi GPON (Gigabit Passive Optical Network)”. Transmisi. 18(1):30-7.

[4] Kustanto, Saputro D. (2015) Belajar Jaringan Komputer Berbasis Mikrotik. 1st ed. Surakarta: Gava Media.

[5] Maslan A, and Wangra T. (2012). Belajar Cepat Teori, Praktek dan Simulasi Jaringan Komputer dan Internet. 1st ed. Jakarta: BADOUSE.

[6] Fitriawan H, Wahyudin A. (2014). "Simulasi Kinerja Jaringan Nirkabel IEEE-802.11a dan IEEE802.11g Menggunakan NS-2”. J Rekayasa Elektr. 10(4):161-5.

[7] Rasudin. Quality of Service (Qos) Pada Jaringan Internet Dengan Metode Hierarchy Token Bucket. J Penelit Tek Inform. 2014;4(1):209-23.

[8] Hantoro, Dwi G. (2015). Fiber Optik: Teknologi, Material, Istalasi, dan Implementasi. Bandung: Informatika Bandung.

[9] Muslim MA, Pramesti AA. (2014) "Penyajian Data Pelanggan pada Lima Area PT. Telekomunikasi Indonesia, Tbk". Sci J Informatics. 1(2):193-200.

[10] Sudrajat I, Yasdinul H, Faiza D. (2014). “Analisis Redaman Serat Optik Terhadap Performansi Skso Menggunakan Metode Link Power Budget (Studi Kasus Pada Link Padang-Bukittinggi di PT. Telkom Padang)" Ilham. VOTEKNIKA. 2014;2(2):48-55.

[11] Sugiyono. (2012). Memahami Penelitian Kuantitatif. Bandung: Alfabeta.

[12] Pranata YA, Fibriani I, Utomo SB. (2016). "Analisis Optimasi Kinerja Quality of Service Pada Layanan Komunikasi Data Menggunakan NS - 2 di PT. PLN (PERSERO) Jember”. Sinergi. 20(2):149-56. 